\title{
On Address
}

Adrian Haddock

University of Stirling

\begin{abstract}
When someone thanks someone for something, or advises him against something, or refuses something from him, his action is directed not merely at but to the other. He addresses the other. But is it only actions that exemplify this mode of directedness? This essay argues that it is not.
\end{abstract}

1. We can single out a class of speech acts by the following feature: they are directed to another. When one thanks another for something, or advises them against something, or refuses something from them, one speaks not (or not only) about them, but to them. One addresses them. This is a relation that one stands in to them. To understand these acts is (inter alia) to understand this relation. More fully, it is is to understand a neglected manner or mode of de re intentionality: a manner of relational directedness that is not merely directedness at a particular object, but directedness to (a fellow) subject.

2. How should we understand this manner of intentionality? We find it exemplified in intentional actions-specifically, in speech acts-such as those just mentioned. An intentional action is a realisation or an execution of a 
practical thought-an intention, or volition, or desire. Here, then, is a suggestion: only when a suitable practical thought is realised is this manner of intentionality exemplified; outside of the context of an intentional action of the relevant sort (such as a speech act), it is not to be found.

3. My central aim in this essay is to undermine this suggestion. I will outline an influential account of intentional actions that exhibit this mode of intentionality—an account due to Jennifer Hornsby. ${ }^{1}$ And I will suggest that it is a consequence of this account that this mode of intentionality must be exhibited not only in realised practical thoughts of the sort the account articulates, but in other contexts too; specifically, in unrealised practical thoughts-pure intentions, or volitions, or desires. ${ }^{2}$

4. Let us call the intentional actions that Hornsby's account accounts for actions of address. For there to be an action of this sort, the following conditions must be satisfied: first, there must be two subjects-an addressor, $\mathrm{X}$, and an addressee, $\mathrm{Y}$; second, $\mathrm{X}$ must have a volition to address $\mathrm{Y}-\mathrm{X}$ must try to address $Y ; 3$ third, $Y$ must recognise that $X$ is trying to address $Y$-only if $Y$ recognises this is X's practical thought realised. ${ }^{4}$

5. What is the content of this practical thought-this volition? Specifically, how does it represent $Y$ ? $X$ might express this thought by saying "I am trying to 
address ... " (for example, "I am trying to advise ... against eating margarine"). In the thought $X$ thereby expresses, what manner of representation of $Y$ takes the place of the dots?

6. It cannot be a merely general representation - "I am trying to address another". $\mathrm{X}$ is not merely trying to address an other-any old other-but a particular other, Y.

7. We might think we can deal with this by introducing, into the content of the practical thought, a demonstrative element that serves to single out $\mathrm{Y}$ from the manifold of subjects-"I am trying to address this person". That is an element of singular thought constituted by perception: it is through perceiving $Y$-standing to $Y$ in that relation-that $X$ singles out $Y$ in this way. And it can seem to be exactly what we need.

8. But this content seems to be inadequate, by the lights of Hornsby's account. For her account holds that, for the volition to be realised, $\mathrm{Y}$ must recognise that $\mathrm{X}$ is trying to address $\mathrm{Y}$. And it seems clear how this thoughtY's recognition-represents $Y$. It does not represent $Y$ in the perceptualdemonstrative manner, as this person. (Perhaps we can imagine recherché cases in which it does; but in the typical case, it does not-and that is all we need be concerned with here.) It rather represents $Y$ in the first personal manner; it is the thought that $Y$ could express by saying " $X$ is trying to address me"-the thought that $X$ is trying to address $Y$ herself, as we might say. ${ }^{5}$ 
9. This thought, however, does not merely represent $Y$ in this manner; it represents X's volition as itself representing $Y$ in this manner. And this thought is not merely a thought; it is recognition-and so, knowledge. So, the way it represents X's volition as representing Y must be the way that X's volition represents $Y$. X's practical thought must represent $Y$ as $Y$ herself-it must represent $Y$ in the very manner (what I earlier called "the first personal manner") through which Y's recognition itself represents Y. But according to the above suggestion, X's practical thought represents $Y$, not in this way, but precisely in the perceptual-demonstrative way. Given this, Y's thought is not knowledge; it represents $X$ as having a volition that $X$ does not have. To have a thought about $X$ 's volition that is knowledge, $Y$ would have to think, instead, that $X$ is trying to address this person. But this cannot be the thought that Y's recognition consists in, if $Y$ 's recognition represents $Y$ in the first personal way, for $Y$ could endorse that thought and still wonder "Is he trying to address me?" Y's recognition is knowledge of how X's volition represents $Y$; so, if Y's recognition represents $Y$ in this way, so does $X$ 's volition.

10. The upshot is that, because $Y$ 's recognition does represent $Y$ in the first personal manner, so does X's volition. The verbal expression for this manner of representation, on Y's lips, as it applies to $Y$, is "me". On X's lips, its verbal expression, as it applies to $\mathrm{Y}$, is "you". So, the answer to the question of $\S 3$ is- "I am trying to address you". This is not a perceptual-demonstrative way of thinking. And yet, just like such a manner of thinking, it is an element of 
singular thought. It is the first person way of thinking. What is distinctive about this practical thought is that it thinks in this way, not merely of the subject of the thought, but of another subject. So, there is something misleading about simply calling this the first person way of thinking. It is equally the second person way.

11. The difficulty for the suggestion (of §2) can now be stated. X's volition to address $\mathrm{Y}$, whether it is realised in action or not, is such as to represent $\mathrm{Y}-$ the one to whom the putative act of address is directed-in the first/second person manner; it represents $\mathrm{Y}$ in the manner expressible by $\mathrm{X}$ with "you", and by $\mathrm{Y}$ with "me". Such a volition just is an exemplification of the mode of de re intentionality which is the topic of this essay. In having this volition, $\mathrm{X}$ does not merely think about or of $\mathrm{Y} ; \mathrm{X}$ thinks towards $\mathrm{Y}$. Directedness to a fellow subject is a property of the practical thoughts that inform speech acts, whether or not these thoughts are realised in intentional actions. So, it cannot be that the present mode of intentionality is exemplified merely in realised practical thought; it must be exemplified in pure practical thought as well.

12. We can put the point by saying that our topic is a mode of intentionality which is not merely de re, but de se, and de se towards anotherfor $X$ thinks of $Y$ as $Y$ herself; $X$ 's thought represents $Y$ in the very manner that $Y$ represents $Y$ when $Y$ thinks of herself in that manner which she can express with "me". And this is a manner that can be exemplified not just in intentional actions-such as speech acts-but also in pure practical thoughts. 
III

13. This conclusion opens into a further issue, which I would like to end by raising.

14. It is an integral feature of Hornsby's account that X's volition to address $Y$ is realised only if $Y$ recognises that $X$ intends to address $Y$ herself. Combining that feature with the suggestion (of §2) yields the thought that it is a condition of X's thinking towards $Y$ - of $X$ 's thinking of $Y$ in the first/second person manner-that $Y$ recognises that $X$ thinks of her in this manner. ${ }^{6}$ For only if she so recognises this is X's volition realised, and, according to the suggestion (of §2), only if X's volition is realised is our manner of de re/de se intentionality exemplified-the manner that is X's thinking towards Y. Of course, it cannot be right that the manner is exemplified only if X's volition is realised; it is exemplified even if X's volition remains pure. And perhaps this condition should be weakened so that it says merely that $Y$ is able to recognise that $X$ thinks of her in this manner. But something like this seems needed in order to distinguish the present mode of de re/de se intentionality from the mode of de re intentionality exemplified in perceptual-demonstrative thinking: in both, it is a condition of the mode's exemplification that the object thought about in this manner exists; but in the former, there is the further condition that the object is a subject who is able to recognise that she is thought about in this manner, and therefore is able to think of herself as herself. 
15. But this raises a question. It seems that $X$ can have a pure practical thought directed towards $Y$ even if $X$ does not engage in any overt addressive actions, or indeed in any overt behaviour at all which is in any sense informed by the thought at issue. And yet, it is a condition of X's having such a de re/de se thought about $Y$ that $Y$ is able to recognise that she is thought of by $X$ in this way-whether the thought is realised in action, or expressed in behaviour, or not. How is this possible? For there to be something for $Y$ to recognise, $X$ 's thought must be in some sense publically available. But how could X's thought be publically available, if it is not expressed either in addressive actions, or in non-intentional but still expressive behaviour (such as "pain-behaviour") on X's part?

16. It is an assumption of this difficulty that (as we might put it) $X$ has (or is) a body: $\mathrm{X}$ is present in the public world, and is capable of realising thoughts in intentional action and expressing thoughts in behaviour. The difficulty is that it seems that $X$ can have thoughts towards another that are neither so realised nor so expressed-and yet are such as to be apprehensible by the one to whom they are directed nonetheless. It cannot be through X (or his body's) doing anything to make these thoughts publically available that they are made available-be it moving in distinctive ways, or striking distinctive poses, either of which might be considered manifestations of the thoughts' presence.7 How then can X (or his body) make them available? The answer is: not by doing anything, but simply by being. It is not through engaging in action, or having a 
distinctive gait etc., that $X$ (or his body) makes his thought available to $Y$, but simply through being (or having) a body with the kind of articulation that he (his body) has.

17. This was the view of J.G. Fichte-it is central to his Foundations of Natural Right. And it seems to be a view we need. It says that having (or being) a body is, as such, the expression of a thought directed towards anyone with the ability to recognise that they are being thought towards. As we might put it: simply in having (or being) the bodies we do (or are), we think towards anyone who is able to acknowledge our address in return. Address is not merely a character of intentional actions. It is to be found wherever thinking towards another is to be found. And thinking towards another, the recognisable actuality that it is, is to be found wherever there is a body with the kind of articulation that our bodies (we) have. The human body is an act of address. ${ }^{8}$

18. In the context of contemporary Anglophone philosophy-and perhaps in other contexts too'-this is a highly unfamiliar idea. But-as far as I can seeit is an idea that we need, in order to make sense of the special mode of de re/de se intentionality that is our topic. We began by trying to understand this manner by thinking through Hornsby's account of addressive action. We have ended with Fichte's conception of the body.

\section{NOTES}

1. Jennifer Hornsby, "Illocution and its Significance," in Savas L. Tsohatzdis (ed.) Foundations of Speech Act Theory: Philosophical and Linguistic Perspectives (London: Routledge, 1994), pp. 187-207. 

Donald Davidson, "Intending" (1978), reprinted in his Essays on Actions and Events (Oxford: Clarendon Press, 2001). It is worth stressing that the idea of pure practical thought only covers practical thought that is not so much as in the process of realisation; it does not cover practical thought that was, but for some reason did not achieve completion. The latter would still count as realised, in the present sense of "realised", because it would not be pure. On the relevant temporal distinctions here-which are of vital importance for practical philosophy-see Michael Thompson, "Naïve Action Theory", in his Life and Action: Elementary Structures of Practice and Practical Thought (Cambridge, Mass.: Harvard University Press, 2008).

3. It would not affect anything I want to say if the relevant practical thought was weakened to an intention to address Y, or even to a desire to address Y. But, in what follows, I shall follow the letter of Hornsby's account.

4. Again, this could be weakened without affecting anything I want to say-to the condition that Y must be able to recognise this (although I do not claim that Hornsby could accept this weakening).

5. See Peter Geach, "On Beliefs About Oneself”, Analysis, vol. 18, no. 1 (1957): 23-24. See also Sebastian Rödl, SelfConsciousness (Cambridge, Mass.: Harvard University Press, 2007), to which I am much indebted.

6. The requirement is not that $\mathrm{Y}$ recognises what $\mathrm{X}$ is thinking (for instance, that $\mathrm{X}$ intends to advise her herself against eating margarine). It is merely that $\mathrm{Y}$ recognises that $\mathrm{X}$ is thinking of her herself.

7. On this topic, see (of course) John McDowell, "Criteria, Defeasibility, and Knowledge" (1982), reprinted in his Meaning, Knowledge, and Reality (Cambridge, Mass.: Harvard University Press, 2008).

8. J.G. Fichte, Foundations of Natural Right, trans. Michael Baur (Cambridge, Cambridge University Press, 2000): “... my body would have to exercise an efficacy by virtue of its shape and its mere existence in space [an influence] exercised upon a rational being as rational" (p. 70). I think a proper development of the present suggestion would have to acknowledge that the act of address is, not something that happens only at certain times, but the time-general character of the human body as such ("this appearance of my body must be such that it cannot be understood or comprehended except under the presupposition that I am a rational being", p. 71). For a development of this idea, see Sebastian Rödl, “Intentional Transaction”, Philosophical Explorations, vol. 17., no. 3 (2004): 304-316.

9. It does not figure, for example, in the recent exchange between Dreyfus and McDowell. See Hubert L. Dreyfus, "Overcoming the Myth of the Mental: How Philosophers Can Profit from the Phenomenology of Everyday Experience", Proceedings and Addresses of the American Philosophical Association, vol. 79, no. 2 (November 2005), and John McDowell, “What Myth?”, Inquiry, vol. 50, no. 4 (2007): 338-351. 